\title{
Spiroplasma eriocheiris Adhesin-Like Protein (ALP) Interacts with Epidermal Growth Factor (EGF) Domain Proteins to Facilitate Infection
}

\author{
Libo Hou ${ }^{1}$, Yuhan Liu ${ }^{1}$, Qi Gao ${ }^{1}$, Xuechuan Xu ${ }^{1}$, Mingxiao Ning ${ }^{1}$, Jingxiu Bi ${ }^{1}$, Hui Liu ${ }^{1}$, \\ Min Liu ${ }^{1}$, Wei Gu ${ }^{1,2}$, Wen Wang ${ }^{1}$ and Qingguo Meng ${ }^{1,2 *}$ \\ 1 Jiangsu Key Laboratory for Biodiversity and Biotechnology and Jiangsu Key Laboratory for Aquatic Crustacean Diseases, \\ College of Life Sciences, Nanjing Normal University, Nanjing, China, ${ }^{2}$ Co-Innovation Center for Marine Bio-Industry \\ Technology of Jiangsu Province, LianYungang, China
}

OPEN ACCESS

Edited by: Mario Alberto Rodriguez, CINVESTAV, MexicO

Reviewed by: Patricia Talamás-Rohana, CINVESTAV, Mexico

César López-Camarillo, Universidad Autonoma de la Ciudad de Mexico, Mexico

${ }^{*}$ Correspondence:

Qingguo Meng mlzzcld@aliyun.com

Received: 07 November 2016 Accepted: 10 January 2017 Published: 26 January 2017

Citation: Hou L, Liu Y, Gao Q, Xu X, Ning M, Bi J, Liu H, Liu M, Gu W, Wang W and Meng Q (2017) Spiroplasma eriocheiris Adhesin-Like Protein (ALP) Interacts with Epidermal Growth Factor (EGF) Domain Proteins to Facilitate Infection.

Front. Cell. Infect. Microbiol. 7:13. doi: 10.3389/fcimb.2017.00013
Spiroplasma eriocheiris is a novel pathogen found in recent years, causing the tremor disease (TD) of Chinese mitten crab Eriocheir sinensis. Like Spiroplasma mirum, S. eriocheiris infects the newborn mouse (adult mice are not infected) and can cause cataract. Adhesion-related protein is an important protein involved in the interaction between pathogen and host. In this study, the Adhesin-like Protein (ALP) of S. eriocheiris was detected on its outer membrane by using immune electron microscopy, and was found to be involved in the bacterium's infection of mouse embryo fibroblasts (3T6-Swiss albino). Yeast two-hybrid analysis demonstrated that ALP interacts with a diverse group of mouse proteins. The interactions between recombinant partial fibulin7 (FBLN7; including two epidermal growth factor [EGF] domains) and ALP were confirmed by Far-western blotting and colocalization. We synthetized the domains of FBLN7 [EGF domain: amino acids 136-172 and complement control protein (CCP) domain: 81-134 amino acids], and demonstrated that only EGF domain of FBLN7 can interact with ALP. Because the EGF domain has high degree of similarity to EGF, it can activate the downstream EGFR signaling pathway, in key site amino acids. The EGFR pathway in 3T6 cells was restrained after rALP stimulation resulting from competitive binding of ALP to EGF. The unborn mouse, newborn mouse, and the adult mouse with cataract have a small amount of expressed FBLN7; however, none was detected in the brain and very little expression was seen in the eye of normal adult mice. In short, ALP as a S. eriocheiris surface protein, is critical for infection and further supports the role of ALP in S. eriocheiris infection by competitive effection of the EGF/EGFR axis of the target cells.

Keywords: Spiroplasma eriocheiris, adhesin-like protein, 3T6-Swiss albino, epidermal growth factor, fibulin7

\section{IMPORTANCE}

S. eriocheiris has been previously identified as a novel pathogen of E. sinensis and caused mass mortality in aquaculture. It is interesting that $S$. eriocheiris has the ability to infect $3 \mathrm{~T} 6$ cells other than invertebrates such as crustaceans. However, how it infects the host cells and its cellular molecular pathogenesis is poorly understood. Adhesin-like protein (ALP) plays an important role 
in this process. We demonstrated that S. eriocheiris ALP is critical for the bacterial infection of host cells, and may be important in finding ways to prevent host cell infection.

\section{INTRODUCTION}

Spiroplasma eriocheiris is a causative agent of the tremor disease (TD) of Chinese mitten crab Eriocheir sinensis (Wang et al., 2003, 2011), and a novel pathogen of aquatic crustaceans including Procambarus clarki, Penaeus vannamei, Macrobrachium rosenbergii, and Macrobrachium nipponense (Bi et al., 2008; Liang et al., 2011; Xiu et al., 2015). Historically, the Spiroplasma spp. were known to associate with only insects, ticks, and plants; however, recent isolations from crustaceans are beginning to change our understanding of the host range (Regassa and Gasparich, 2006). Phylogenetic analysis of the 16S rDNA gene sequences of $S$. eriocheiris showed that this Spiroplasma strain had a close relationship with $S$. mirum (Wang et al., 2004a). S. mirum isolated from the rabbit tick (Haemaphysalis leporispalustris) can infect vertebrates (Kirchhoff et al., 1981; Tully et al., 1982). It induced the presence of suckling mouse cataract agent (SMCA) (Zeigel and Clark, 1974). Similarly, $S$. eriocheiris was detected in the brain of embryonated chickens (Wang et al., 2003), and it was shown to infect the newborn mouse and cause cataract; adult mice are not infected (Figure S1). Therefore, it is important to study how $S$. eriocheiris infects mouse cells and its cellular molecular pathogenesis.

Presently, several lines of evidence suggest that host-pathogen interactions could be a prerequisite for invasion and colonization of bacteria (Wayadande and Fletcher, 1998; Ammar and Hogenhout, 2005; Suzuki et al., 2006; Ojogun et al., 2012; Kahlon et al., 2013). Mollicutes lack a cell wall (Stülke et al., 2009), and it is well-established that successful colonization of the host cells requires adhesion as the first step. Adhesion of Mycoplasma and Spiroplasma to host cells is a prerequisite for colonization by the parasite and subsequent infection; hence, adhesion-related proteins play an important role in this process (Rottem, 2002; Balish et al., 2003). The loss of adhesion capacity by mutation results in loss of infectivity, while reversion to the cytadhering phenotype is accompanied by regaining infectivity and virulence (Krause et al., 1982, 1983). Entry of S. eriocheiris involves interaction between the pathogen and host that induces cellular signaling events. However, few studies have focused on how the adhesion-related protein interacts with the host protein. We have been studying the role of $S$. eriocheiris adhesin-like protein (ALP) in the infection of E. sinensis (Meng et al., 2010). However, the role and the host interaction proteins of ALP in the process of $S$. eriocheiris infect mouse cells have not yet been defined.

In this study, we demonstrated that ALP is located in the $S$. eriocheiris membrane and we used a yeast (Saccharomyces cerevisiae) two-hybrid ( $\mathrm{Y} 2 \mathrm{H})$ assay to identify molecular ALPhost interaction proteins with distinct molecular functions, suggesting that it plays an important and complex role in the process of bacterial entry into the host cell.

\section{MATERIALS AND METHODS}

\section{S. eriocheiris Culture, Host Cell Culture, and Treatment}

$S$. eriocheiris was isolated from E. sinensis with TD using the methods described by Wang et al. (2004b) and cultured in $\mathrm{R} 2$ medium at $30^{\circ} \mathrm{C}$ (Moulder et al., 2002). 3T6-Swiss albino (3T6) cells were purchased from the Type Culture Collection cell bank of the Chinese Academy of Sciences Committee (Shanghai, China) and Human cervical epithelial adenocarcinoma (HeLa) cells from Professor Chen's lab. The cells were cultured in Dulbecco's modified Eagle's medium (DMEM), (Wisent, Canada) complete medium supplemented with $10 \%$ fetal bovine serum (FBS), $\quad 0.15 \% \quad \mathrm{NaHCO}_{3}, \quad 0.45 \%$ glucose, $4 \mathrm{mM}$ L-Glutamine (Wisent, Canada), and antibiotics $\left(100 \mathrm{U} \mathrm{ml}^{-1}\right.$ penicillin, 100 $\mathrm{U} \mathrm{ml}^{-1}$ streptomycin) at a suitable $\mathrm{pH}$ of 7.20-7.40.

When the cell cultures grew to $>70 \%$ confluence, they were treated in the following ways: (1) $3 \mathrm{~T} 6$ cells were treated with S. eriocheiris (S. eriocheiris groups) for $36 \mathrm{~h}$; (2) 3T6 cells were infected with $S$. eriocheiris, which was treated with anti-ALP (1:2000) for $1 \mathrm{~h}$ at $30^{\circ} \mathrm{C}$ (S. eriocheiris+Anti-ALP groups), and incubated for $36 \mathrm{~h}$; (3) $3 \mathrm{~T} 6$ cells were infected with S. eriocheiris, which was treated with pre-immume serum for $1 \mathrm{~h}$ at $30^{\circ} \mathrm{C}(\mathrm{S}$. eriocheiris+serum groups), and incubated for $36 \mathrm{~h}$; (4) $3 \mathrm{~T} 6$ cells were treated with recombinant ALP $(5 \mu \mathrm{g} / \mathrm{ml})$ for $0,15,30$, 45, and $60 \mathrm{~min}$ (using $0 \mathrm{~min}$ as control); (5) 3T6 cells were treated with EGF $(20 \mathrm{ng} / \mathrm{ml})$ and using different concentrations of recombinant $\operatorname{ALP}(0,0.5,1,5$, and $10 \mu \mathrm{g} / \mathrm{ml})$ for $15 \mathrm{~min}$, cells without any treatment served as a control; (6) HeLa cells were co-transfected with plasmids encoding EGFP-ALP and DsRedFiblin7, using X-tremeGENE HP DNA Transfection Reagent (Roche) according to the supplier's instructions. The all host cells were culture with same conditions $37^{\circ} \mathrm{C}$ and $5 \% \mathrm{CO}_{2}$.

\section{Antibodies}

Rabbit anti-ALP antibodies and polyclonal antibody against $S$. eriocheiris have been described previously (Meng et al., 2010). Other antibodies used in this study were mouse anti-Glyceraldehyde-3-phosphate dehydrogenase (GAPDH), mouse-anti extracellular regulated protein kinases (ERK), Phospho-mouse-anti extracellular regulated protein kinases (p-ERK), mouse-anti Ras homolog gene family, member A (RhoA), mouse-anti Phospho-Ras homolog gene family, member A (p-RhoA), mouse-anti $\beta$-Catenin, mouse-anti Phospho- mouse $\beta$-Catenin, mouse anti Akt, mouse-anti Phospho-Akt, anti-GST tag, and Alexa Fluor 488-labeled Goat Anti-Rabbit IgG (Beyotime, China) and Goat antimusculus fibulin7 (FBLN7) (Cell Signaling, USA). All antibodies used for immunofluorescence were tested by the vendor to ensure the specificity and confirmed by western blotting, immunofluorescent microscopy, or both.

\section{Immuno-EM}

For Immuno Gold Electron Microscope (EM), the S. eriocheiris cells bound to EM grids were treated with Triton solution containing $0.3 \%$ Triton X-100, fixed using 3\% paraformaldehyde, and $0.1 \%$ glutaraldehyde in phosphate buffer saline (PBS) for 
10 min at RT, and washed three times by PBS. The cells structures on grids were treated by applying 10-fold diluted ALP polyclonal antibody in PBS containing 2\% BSA, and subsequently washed five times using PBS. Then, the cell preparations were treated by applying 10-fold diluted gold-labeled secondary antibody $(5 \mathrm{~nm}$ colloidal-gold-labeled goat antibody; Sigma) in PBS containing $2 \% \mathrm{BSA}$ for $30 \mathrm{~min}$ at RT, washed five times, and then stained by $2 \%$ molybdate. The samples were examined using an $\mathrm{H}-7650$ transmission electron microscope (Hitachi, Japan).

\section{Membrane Protein and Cytoplasm Protein of S. eriocheiris Preparation}

Membranes and cytoplasm were isolated from the washed cells as described by Michael Salman (Salman and Rottem, 1995). Briefly, washed bacteria were suspended in a $10 \mathrm{mM} \mathrm{NaCl}$ solution containing $0.5 \mathrm{mM} \beta$-mercaptoethanol and treated for $3 \mathrm{~min}$ at $4^{\circ} \mathrm{C}$ in a W-350 Heat Systems sonicator operated at $50 \%$ duty cycles and an intensity of $200 \mathrm{~W}$. Intact cells were removed by centrifugation at $5000 \times \mathrm{g}$ for $5 \mathrm{~min}$, and membranes were then collected by centrifugation at $34,000 \times \mathrm{g}$ for $40 \mathrm{~min}$. The supernatant containing cytoplasmic protein and the centrifuged pellet were each washed once and resuspended in $10 \mathrm{mM} \mathrm{NaC1}$ solution. Protein concentration was determined by the BCA method with bovine serum albumin as a standard. The proteins were detected by $12 \%$ SDS-polyacrylamide gel electrophoresis (SDS-PAGE).

\section{Immunofluorescence Experiment}

In the cell challenge test, samples were collected every $2 \mathrm{~h}$ between 30 and $48 \mathrm{~h}$ post challenge and washed three times with PBS. Then, the 3 T6 cells were fixed with $4 \%$ paraformaldehyde and permeated with PBS containing $0.1 \%$ Triton X-100 for $30 \mathrm{~min}$. After the cells were incubated with 3\% BSA in PBST for $30 \mathrm{~min}$, the ALP polyclonal antibody, incubated with $S$. eriocheiris, was used to inhibit adhesion to and infection of 3T6 cells. The cells infected with $S$. eriocheiris (cells without treatment and $S$. eriocheiris treated with pre-immume serum served as the control. Then, the cells were incubated with Alexa Fluor 488-conjugated goat anti-rabbit IgG secondary antibody (Invitrogen, USA) and examined using a Ti-s inverted phasecontrast microscope (NikonH600L, Japan).

\section{Yeast Two-Hybrid System}

A Clontech Matchmaker Two-Hybrid system, yeast media and supplements, vectors, and yeast transformation system was used.

\section{Cloning of S. eriocheiris ALP Gene and Autoactivation Test}

The full-length sequence of ALP (GenBank accession number GU046560) gene was amplified by PCR from S. eriocheiris genomic DNA using the specific primers (ALP; Table 1). After site-directed mutagenesis (ALP-M), it was cloned into the Sal I/EcoR I site of pGBKT7 vector containing the GAL4 DNA-BD.

To examine whether the bait (ALP) autonomously activated (autoactivated) the reporter genes in yeast (S. cerevisiae) strain AH109 in the absence of a prey protein, AH109 cells were
TABLE 1 | Primers used for cloning the EIF2, FBLN7, and ALP.

\begin{tabular}{ll}
\hline Name & Sequence $\left(\mathbf{5}^{\prime} \mathbf{-} \mathbf{3}^{\prime}\right)$ \\
\hline EIF2-F & GAAGGATCCATGGCATCGGCGGTGGTTG \\
EIF2-R & GTGGCGGCCGCTTCTCACACGTCACTAGCC \\
FBLN7-F & GAATTCTCCACCTGAGCAGCACCACG \\
FBLN7-R & GAGCTCACGGCTGTTCCCACCCACGAT \\
ALP41-F & CCGAATTCATGTTGGCCTGTTCAACT \\
ALP41-R & ATGTCGACTTAGTTTTTCATAATACCAAATTCC \\
ALP41-M-F & TAATGCGTTAGTTAGTGACC \\
ALP41-M-R & ATTTCCCACCACTCATCACT \\
\hline
\end{tabular}

transformed with bait plasmid pGBKT7-ALP and plated on SD/Trp medium, transformed with pGBKT7-empty vector as the negative and pCL1 vector as the positive controls. The results were obtained using $\beta$-galactosidase by Colony-lift Filter Assay (Lin et al., 2005; Liu et al., 2010). Briefly, AH109 yeast cells transformed with empty plasmid, and pGBKT7-ALP positive control plasmid were cultured on SD/-Trp agar plates at $30^{\circ} \mathrm{C}$ for 2-4 days. A clean and dry filter was placed over the surface of the agar plate until evenly wetted, carefully lifted off, and transferred to a pool of liquid nitrogen for $10 \mathrm{~s}$. After thawing at room temperature, the filter was placed with colonies facing up on another filter presoaked in $\mathrm{Z}$ buffer/X-gal solution and incubated at $30^{\circ} \mathrm{C}$ for up to $8 \mathrm{~h}$, checking periodically for the appearance of blue colonies.

\section{Yeast Two-Hybrid Assay}

The Mate \& Plate ${ }^{\mathrm{TM}}$ Library-Universal Mouse (Normalized) Clonetech, a high-complexity cDNA library cloned into the yeast GAL4 activation domain (GAL4-AD) vector pGADT7-Rec and pre-transformed into S. cerevisiae host strain Y187, was mated with bait strain AH109 containing pGBKT7-ALP according to the manufacturer's protocol. Positive clones expressing prey proteins interacting with ALP (bait) were selected on minimal synthetically defined (SD) quadruple-dropout (QDO) medium (SD medium without Ade, His, Leu, and Trp [SD/-Ade/-His/Leu/-Trp]) supplemented with 5-bromo-4-chloro-3-indolyl- $\alpha$ D-galactopyranoside (X- $\alpha-\mathrm{Gal})$ and aureobasidin A (QDO/X/A). The colony-lift filter assay was also used. Normal-sized blue colonies were segregated three times on SD double-dropout (DDO; SD medium without Leu and Trp [SD/-Leu/-Trp]) plates containing $\mathrm{X}-\mathrm{Gal}(\mathrm{DDO} / \mathrm{X})$, and the prey cDNA inserts were amplified by colony PCR.

\section{Confirmation of Positive Interactions by Cotransformation}

The prey plasmid responsible for positive interactions was rescued from segregated colonies using an Easy yeast plasmid isolation kit (Clontech, USA), transformed into Escherichia coli $\mathrm{DH} 5 \alpha$, and isolated. To distinguish positive from false-positive interactions, AH109 yeast cells were cotransformed with bait (pGBKT7-ALP) and prey plasmids. The positive interactions were confirmed by selection on SD/-Trp/-Leu and detected through $\beta$-galactosidase by Colony-lift Filter Assay. 


\section{Recombinant Proteins Expression and Synthesis of Peptides Fragment}

To confirm interactions between bait and prey proteins identified by $\mathrm{Y} 2 \mathrm{H}$, the Mus musculus E74-like factor2 (EIF2, full length) and fibulin7 (FBLN7, 211-382aa, containing two EGF domains) were cloned using the specific forward primer and the reverse primer listed in Table 1. The PCR products were each digested with restriction enzymes and cloned into pGEX4T-1 vectors (containing a GST tag), namely, pGEX-EIF2 and pGEX-FBLN7. Afterward, E. coli BL21 (DE3) was transformed with the resulting recombinant plasmid for IPTG (isopropyl $\beta$-D-1thiogalactopyranoside)-induced recombinant expression (final IPTG concentration of $0.5 \mathrm{mM}$ ). The induction temperature for protein production was $37^{\circ} \mathrm{C}$. The proteins were detected on $12 \%$ SDS-PAGE and western blots.

FBLN7 is 440 amino acids long, contains four distinct domains: a complement control protein (CCP) domain (amino acids 81-134), and three EGF domains (amino acids 136-172, 225-270, 174-320; de Vega et al., 2007). The recombinant FBLN7 protein (amino acids 211-382) contains two distinct EGF domains. The other two domains, CCP domains (amino acids 81-134) and EGF domains (amino acids 136-172), were artificially synthesized (China Peptides Shanghai China).

\section{Far-Western Blotting Analysis}

To confirm ALP interaction with the proteins EIF2 and FBLN7, far-western blotting analysis was performed. Because the recombinant protein contains a GST tag, GST tag protein was used as a negative control. Briefly, EIF2, FBLN7, and GST tag were separated on $12 \%$ SDS-PAGE and transferred onto a PVDF membrane. The membrane was then incubated with wash buffer (2 M Tris, pH 7.5 containing $500 \mathrm{mM} \mathrm{NaCl}$, and $0.1 \%(\mathrm{v} / \mathrm{v})$ Tween-20) containing 5\% BSA for $2 \mathrm{~h}$ at room temperature to block non-specific protein binding. The membrane was washed with wash buffer, and incubated with $25-\mu \mathrm{g}$ His-ALP in $5 \mathrm{~mL}$ of wash buffer containing $5 \% \mathrm{BSA}$ overnight at $4{ }^{\circ} \mathrm{C}$. After washing, the integrin-bound protein band was incubated with primary antibodies (rabbit anti-ALP serum), and then were diluted 1:2500 in wash buffer containing 5\% BSA for incubation overnight at $4^{\circ} \mathrm{C}$. Following washing, the blots were incubated with HRPconjugated anti-rabbit IgG (diluted 1:5000 in wash buffer) for $1 \mathrm{~h}$ at room temperature (Egan et al., 2006). Immunoreactive bands were visualized by the enhanced chemiluminescence (ECL) system (Vazyme China). Far-western blotting analysis was also used to confirm ALP interaction with synthetic EGF and CCP. The EGF and CCP protein were separated on 15\% SDS-PAGE and transferred onto a PVDF membrane; the other methods were followed as described above.

\section{Colocalization}

Colocalization was used to further confirm interactions between bait and prey proteins identified by $\mathrm{Y} 2 \mathrm{H}$ in mammalian cells. Briefly, two mammalian expression vectors, pEGFP-N2, and pDsRed-Monomer-N1, which encode an enhanced green fluorescent protein (EGFP) tag and a DsRed (a red fluorescent protein) tag, respectively, were used for generation of C-terminal EGFP-ALP and DsRed-FBLN7 fusion proteins (Tseng et al.,
2010; Lin et al., 2015). The ALP was cloned in-frame upstream of the EGFP tag of pEGFP-N2, while the FBLN7 gene was amplified from GADT7-FBLN7 (containing two distinct EGF domains) and cloned in-frame upstream of the DsRed tag of pDsRed-Monomer-N1. HeLa cells at high confluence were cotransfected with plasmids encoding EGFP-ALP and DsRedFBLN7, using the X-treme GENE HP DNA Transfection Reagent (Roche) according to the supplier's instructions. To study the colocalization at 1 day post-transfection, cells were washed with PBS, fixed with $4 \%$ paraformaldehyde in PBS for $15 \mathrm{~min}$ at room temperature, followed by washing the cells with PBS. The cells were examined and recorded using a confocal microscope (Nikon TI-E-A1R; Nikon) and representative cells were selected and photographed.

\section{Western Blotting Analysis}

After treatment, cells were briefly washed with cold PBS. While on ice, they were lysed in RIPA buffer (50 mM Tris, $\mathrm{pH} 7.2$; $1 \%$ sodium deoxycholate; $150 \mathrm{mM} \mathrm{NaCl} ; 0.1 \%$ sodium dodecyl sulfate; $10 \mathrm{mM} \mathrm{NaF}$; $1 \%$ Triton-X 100; $1 \mathrm{mM} \mathrm{Na}_{3} \mathrm{VO}_{4}$; protease inhibitor cocktail [1:1000]). Lysates were sonicated for $10 \mathrm{~s}$ and centrifuged at $13,000 \times \mathrm{g}$ for $10 \mathrm{~min}$ at $4^{\circ} \mathrm{C}$. Protein concentration was determined by the BCA method with bovine serum albumin as the standard. Equivalent amounts of protein were separated on $12 \%$ SDS-PAGE and transferred onto PVDF membranes. Membranes were incubated with PBS containing 0.05\% Tween 20 and 5\% BSA to block nonspecific binding and were incubated with primary antibodies (ERK antibody, p-ERK antibody, RhoA antibody, $\mathrm{p}$-RhoA antibody, $\beta$-Catenin antibody, $\mathrm{p}-\beta$-Catenin antibody, Akt antibody, p-Akt antibody, and GAPDH antibody), then treated with appropriate secondary antibodies conjugated to horseradish peroxidase. After this, the bands were visualized using ECL. All the Western blotting analysis were repeated on several occasions, and the gray value of the bands was detected with the ImageJ software.

\section{Protein Expression Tendency of FBLN7}

For the developmental analysis of FBLN7 protein expression, we obtained the brains and eyes of mouse from different stages of mouse development. Animals' brains and eyes were obtained at prenatal 3 days; postnatal 6, 12, 24, $60 \mathrm{~h}$; and postnatal 60 days (adult). The mice afflicted with cataracts were treated as described previously (Riederer and Matus, 1985). Previous studies have confirmed that the expression quantity of FBLN7 in the placenta was the highest. Therefore, we selected this tissue as a positive control. The samples were cut into pieces before protein extraction. The method of protein extraction was listed above. The FBLN7 expression was analyzed by western blotting as above. This study was carried out in accordance with the recommendations of Institutional Animal Care and Use Committee of the Nanjing Normal University [SYXK (Jiangsu) 2015-0028].

\section{Statistical Analysis}

Data were analyzed using the SPSS general linear models (GLM) procedure (SPSS 16.0, Chicago, IL, USA) to test for significant differences among treatments. If a significant $(P<0.05)$ 

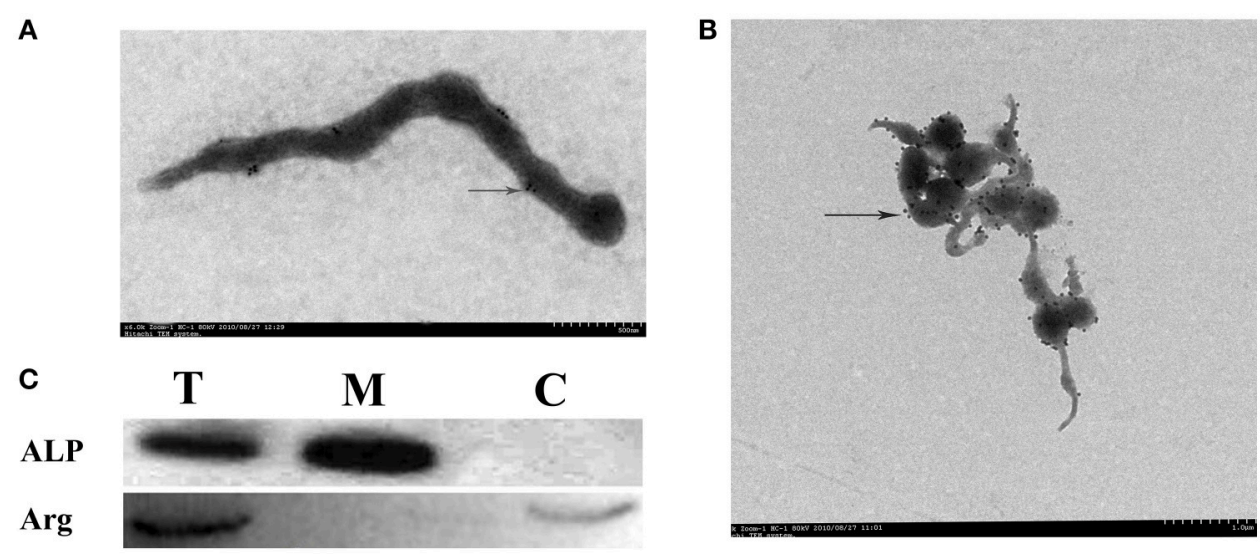

FIGURE 1 | ALP localizes on the surface of S. eriocheiris. (A,B) Immunogold labeling for ALP on the S. eriocheiris. An arrowhead indicates the ALP on the surface of $S$. eriocheiris. (C) Western blotting was used to analyze the location of ALP, three lanes were represented; i.e., all proteins (T), membrane proteins (M), and cytoplasmic protein (C) of S. eriocheiris, respectively.
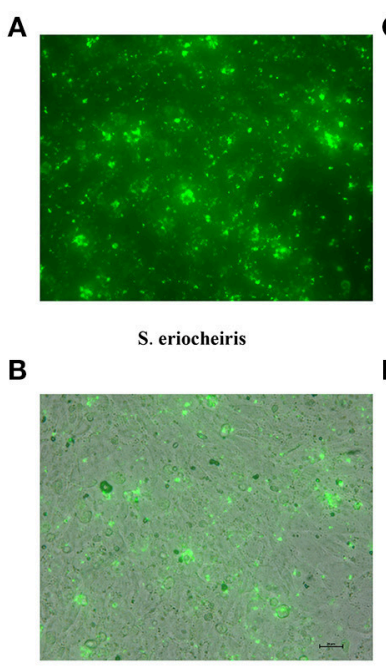

S. eriocheiris (Merge)

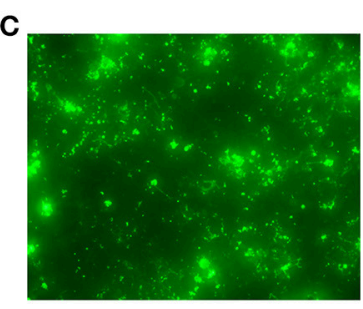

S.eriocheiris+serum

D

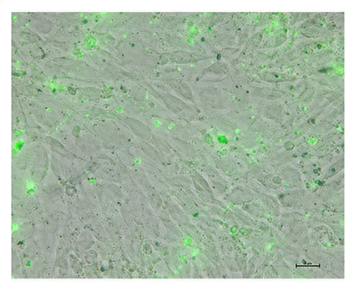

S. eriocheiris+serum(Merge)

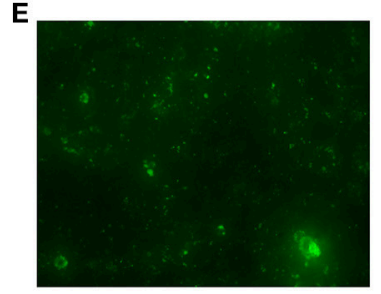

S.eriocheiris+anti-ALP

$\mathbf{F}$

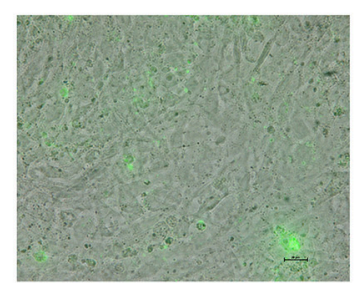

S. eriocheiris+anti-ALP(Merge)
G

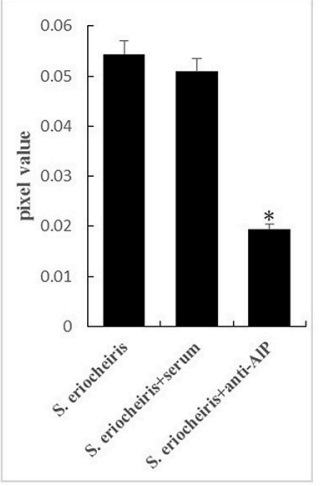

FIGURE 2 | Pretreatment of S. eriocheiris with anti-ALP reduces infection of $\mathbf{3} \mathbf{6}$ cells. Cells treated with S. eriocheiris (S. eriocheiris groups) and S. eriocheiris were incubated with anti-ALP or pre-immume serum (S. eriocheiris+anti-ALP groups or S. eriocheiris+serum) for $36 \mathrm{~h}$. After removal of unbound bacteria, bacteria attached to the host cells were labeled with Alexa Fluor 488-labeled Goat Anti-Rabbit IgG and assessed using confocal microscopy. The green fluorescence represents the bacteria. $(\mathbf{A}, \mathbf{B})$ represent the S. eriocheiris groups: $(\mathbf{A})$ green fluorescence showing the bacteria, and $(\mathbf{B})$ the host cells merging with the green fluorescence. (C,D) represent the S. eriocheiris+serum groups: (C) green fluorescence indicates the bacteria, and (D) the host cells merging with the green, fluorescently-labeled bacteria. (E,F) represent the S. eriocheiris+anti-ALP groups: (E) green fluorescence indicates the bacteria, and (F) the host cells merging with the green, Bars, $20 \mu \mathrm{m}$. (G) The Panels $\mathbf{A}, \mathbf{C}, \mathbf{E}$ unit area pixels value were measured. Statistical significance is indicated with an asterisk ( $\left.{ }^{\star}\right)$.

difference was found, a Duncan's multiple range test (Duncan, 1955) was used to rank the means. All data are presented as mean \pm S.D (standard deviation) of three replicates.

\section{RESULTS}

\section{Surface Localization of ALP}

Firstly, ALP was verified as a surface protein. Transmission EM (TEM) immuno-gold labeling showed that native ALP localizes on the surface of the S. eriocheiris (Figures 1A,B). After preparation of membrane protein, cytoplasmic protein, and total protein of S. eriocheiris, ALP antiserum (dilute1:2000) was used to determine whether immunoaccessible domains were present on the S. eriocheiris surface using western blotting. In agreement with TEM (Figure 1C), the results showed that the ALP signal was detected in the lanes of total protein from S. eriocheiris $(\mathrm{T})$ and membrane proteins (M), but not in cytoplasmic protein (C), thus indicating that ALP is exposed on the surface of $S$. eriocheiris. Arginine deaminase (Arg), as has been previously demonstrated, was one of the $S$. eriocheiris cytoplasmic proteins 
TABLE 2 | Positive hit of the screening.

\begin{tabular}{|c|c|c|c|c|c|c|}
\hline Bait & Prey library & Identical colonies & Positive gene name & $\begin{array}{l}\text { Positive gene } \\
\text { identified }\end{array}$ & $\begin{array}{l}\text { NCBI accession } \\
\text { NMmeber }\end{array}$ & Gene Code match \\
\hline \multirow[t]{23}{*}{ pGBKT7-ALP41 } & \multirow{23}{*}{$\begin{array}{l}\text { Universal Mouse } \\
\text { (Normalized) Clonetech No. } \\
630482\end{array}$} & \multirow[t]{23}{*}{23} & ALP1/ & EUCOMM & JN956676.1 & $\mathrm{NO}$ \\
\hline & & & ALP 9 & & & \\
\hline & & & ALP 2 & KLHL 10 & NM025727.3 & YES \\
\hline & & & ALP 3 & PNPLA 8 & NM026164.2 & YES \\
\hline & & & ALP 4 & NIPAL 3 & NM028995.3 & $\mathrm{NO}$ \\
\hline & & & ALP 5 & FBLN 7 & NM024237.4 & YES \\
\hline & & & ALP 7 & CAR 8 & NM007592.3 & YES \\
\hline & & & ALP 10 & GSg 1 & NM010352.2 & YES \\
\hline & & & ALP 12 & LMPA 2 & NM053261.2 & YES \\
\hline & & & ALP 13 & COPS 5 & NM013715.2 & YES \\
\hline & & & ALP 14 & XPNPEP 1 & NM133216.3 & YES \\
\hline & & & ALP 18 & MCCC 2 & NM030026.2 & YES \\
\hline & & & ALP 19 & SLC34A2 & NM011402.3 & $\mathrm{NO}$ \\
\hline & & & ALP 20 & EIF 2 & NM023502.1 & YES \\
\hline & & & ALP 23 & D3Ertd254e & NM001101478.1 & $\mathrm{NO}$ \\
\hline & & & ALP 29 & KCNJ 15 & NM001271695.1 & $\mathrm{NO}$ \\
\hline & & & ALP 28 & Chromosome 18 & AC102081.15 & $\mathrm{NO}$ \\
\hline & & & ALP 27 & YrDC & NM153566.2 & YES \\
\hline & & & ALP 25 & BCA clone & & $\mathrm{NO}$ \\
\hline & & & ALP 30 & Chromosome 3 & AC093365.10 & $\mathrm{NO}$ \\
\hline & & & ALP 31 & TEX 38 & NM029196.1 & $\mathrm{NO}$ \\
\hline & & & ALP 36 & FOXred 1 & NM172291.1 & YES \\
\hline & & & ALP 37 & YIF1A & NM026553.4 & $\mathrm{NO}$ \\
\hline
\end{tabular}

used as a negative control. The Coomassie stained PAGE gels used in the Western blots in a Supplementary Figure as loading control (Figure S2).

\section{ALP Antibody Inhibition of S. eriocheiris Infection}

To directly show that ALP plays an important role in the process of $S$. eriocheiris infection of 3T6 cells, an immunofluorescence experiment was conducted. The $S$. eriocheiris were incubated with anti-ALP (dilute1:2000) for $1 \mathrm{~h}$ at $30^{\circ} \mathrm{C}$, and then bacterial adhesion and infection of $3 \mathrm{~T} 6$ cells were monitored. The results showed that the quantities of $S$. eriocheiris infection within the 3T6 cell interior were significantly lower than that in the control group at $36 \mathrm{~h}$ post-inoculation (Figure 2 ).

\section{Analysis of S. eriocheiris ALP Interactions with Host Using a Yeast Two-Hybrid System}

To confirm that the bait (ALP) did not autonomously activate (autoactivate) the reporter genes in yeast strain AH109 in the absence of a prey protein, AH109 cells were transformed with bait plasmid pGBKT7-ALP and plated on SD without Trp (SD/-Trp), using the transformed pGBKT7-empty vector as the negative and pCL1 as the positive controls. The results were detected by colony-lift filter $\beta$-galactosidase assay. No blue reaction was detected in colonies with bait plasmid pGBKT7-ALP and pGBKT7-empty, confirming a lack of autoactivation by ALP.

After the yeast two-hybrid screening using yeast mating, a total of 137 yeast colonies with blue color and normal size were observed and selected from SD/-Trp/-Leu/-Ade/His/X/A (QDO/X/A) plates for identification of potential positive clones that exhibited bait and prey protein-protein interactions.

\section{Confirmation of Interactions by Cotransformation}

To confirm the true interactions, 23 colonies were randomly chosen from 137 yeast colonies with blue color. The cotransformation assays were performed in yeast with prey plasmids, and the results showed that all of the selected colonies were a result of interactions with the prey plasmids in yeast. After segregation of the colony three times, yeast colony PCR was performed. This was followed by DNA sequencing to eliminate the duplicate clones and identify interacting targets. Twelve different potentially interacting mouse proteins were identified (Table 2) and the DNA sequencing data for interacting target proteins are provided in Supplementary Data. Interactions in this experiment were confirmed with all these prey proteins (Figure 3, showing interactions of ALP with two prey proteins: FBLN7 and EIF2). 


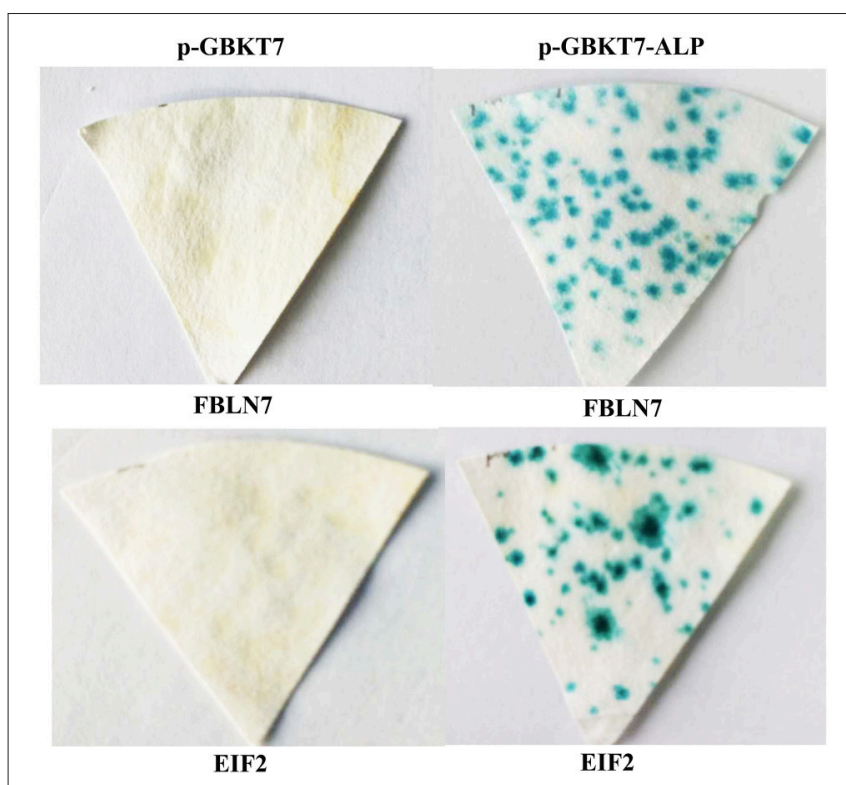

FIGURE 3 | Confirmation of positive interactions in yeast by cotransformation. Y2HGold yeast cells were cotransformed with bait plasmid pGBKT7-ALP and prey plasmid pGADT7-FBLN7 and-EIF2. As a control, pGBKT7 (empty vector) was used to cotransform with each prey plasmid. The positive interactions were confirmed.

\section{Recombinant Protein Expression}

Using yeast two-hybrid screening, several proteins were identified that interacted with $S$. eriocheiris ALP. From among them, two proteins, EIF2 (full length) and FBLN7 (amino acids 211-382), were selected to clone and obtain recombinant protein expression for further studies. After being expressed, recombinant EIF2 and FBLN7 had an apparent molecular weight of around 95 and $43 \mathrm{kDa}$, respectively (Figure S3). The recombinant proteins were purified using a Gel Extraction kit according to the manufacturer's protocol.

\section{Confirmation of Interaction of Identified Proteins with ALP}

In order to further examine the interaction of ALP with EIF2 and FBLN7, Far-western blotting analysis was performed. The results confirmed a direct interaction between ALP and FBLN7 (amino acids 211-382, contain two GEF domains; Figure 4A), none interaction between ALP and GST tage and EIF2. Interactions between ALP and FBLN7 were examined in mammalian (HeLa) cells by cotransfection assay. Immunofluorescence microscopy revealed that ALP and FBLN7 (amino acids 211-382, contain two GEF domains) were colocalized in HeLa cells, and exhibited the strongest colocalization (Figure 4B). The negative control was cotransfected using EGFP-empty and DsRed-empty imported into HeLa cells. The intensity analysis demonstrated that ALP (green curve) and FBLN7 (red curve) had consistent colocalization with morula and revealed a similar pattern of elevated peaks across, and adjacent to, the morula profile
(Figure 4B). ALP and FBLN7 proteins exhibited both diffuse and punctate cytoplasmic colocalization in the cell.

\section{ALP Interact with EGF Domain}

By Far-western blotting analysis and cotransfection assay, we identified interaction between ALP and FBLN7. The FBLN7 has been identified contain four domains (three EGF domains and one CCP domain), and the protein used in the above experiments include two EGF domain. Next, to determine if all sequences, or some special structural domain of FBLN7, were involved in specific interactions with the ALP, two other domains (EGF: 136172 aa and CCP: 81-134 aa domains) were also tested by Farwestern blotting. The results showed that specific bands were found only for the interaction of EGF domains and ALP. The CCP region of FBLN7 did not exhibit any substantial interaction with ALP (Figure 4C). This experiment confirmed that ALP interacted most specifically with the EGF domains of FBLN7.

\section{Recombinant ALP Stimulate 3T6 Cells}

EGF-like domain is an evolutionary conserved protein domain, has high degree of similarity with EGF, can activate downstream pathway of EGFR signaling, in key site of amino acids. To determine whether ALP has an influence on the EGFR signaling, the $3 \mathrm{~T} 6$ cells were treated with $\operatorname{rALP}(5 \mu \mathrm{g} / \mathrm{ml})$ for $0,15,30,45$, and $60 \mathrm{~min}$ at $37^{\circ} \mathrm{C}$, with $5 \% \mathrm{CO}_{2}$. After treatment, the $3 \mathrm{~T} 6$ cell proteins were extracted, and western blotting was used to test variation tendency of ERK and p-ERK (the main downstream pathway of EGFR signaling), using GAPDH as the control. The results showed that the ERK protein underwent no obvious changes after rALP stimulation. The $\mathrm{p}$-ERK protein post rALP induction showed a significant reduction at $15 \mathrm{~min}$. After that, $\mathrm{p}$ ERK had a slight recovery and was also lower than the control group (Figure 5A). The variation tendency was similar to that with S. eriocheiris-induced 3 T6 cells at an early stage (Figure 5B).

\section{Recombinant ALP Inhibits EGF Activation of EGFR Pathway}

To further determined the influence of ALP on the host cells EGFR signaling. After 3T6 cells were treated with EGF and different concentrations of protein, the relative protein (ERK, p-ERK, $\beta$-Catenin, p- $\beta$-Catenin, Akt, p-Akt, RhoA, p-RhoA) expression changes were detected by western blotting. The results showed that as the rALP concentration increased, $\mathrm{p}$ ERK, $\mathrm{p}-\beta$-Catenin, $\mathrm{p}$-Akt, and $\mathrm{p}$-RhoA were significantly reduced compared with the control and the EGF-stimulated groups. The ERK, $\beta$-Catenin, Akt, and RhoA showed no obvious changes after stimulation, when GAPDH was used as a control (Figure 6).

\section{Expression of FBLN7 during Mouse Development}

We have shown that ALP could interact with the EGF domain of FBLN7, thus the FBLN7 may act as one of the adhesion sites in the process of the bacteria infect host cells. In order to demonstrate that ALP interactions with FBLN7 may play an important role during the process of $S$. eriocheiris infection of the newborn mouse, we collected brain and eye samples of mice at different time points to detect the expression of FBLN7. 


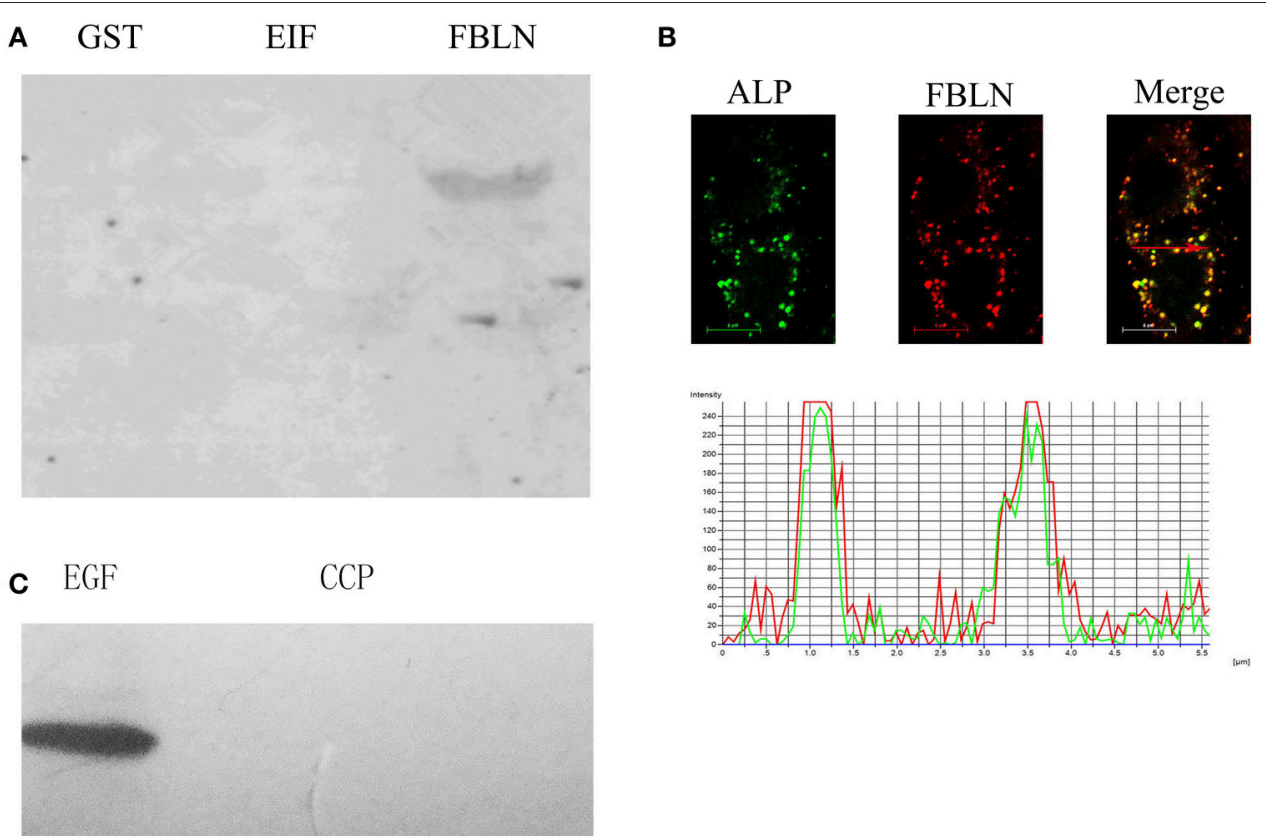

FIGURE 4 | The interaction between ALP and FBLN7. (A) The interaction between ALP and the domain of FBLN7 was detected by far-western blotting. The GST lanes are the control, and EIF and FBLN lanes represent the recombinant EIF and FBLN7, respectively. (B) Colocalization of FBLN7 with S. eriocheiris ALP in HeLa cells. Full-length ALP and partial sequence (amino acids 211-382) FBLN7 cDNAs were cloned into pEGFP-N2 and pDsRed-monomer N1 and transfected into undifferentiated HeLa cells as described in the Materials and Methods Section. Twenty-four hours after transfection, cells were fixed and processed for imaging. Fluorescence microscopy and intensity profiles of HeLa cells, ALP (green), and FBLN7 (red), show colocalization of S. eriocheiris ALP with FBLN7. The red arrows in the fluorescence images indicate the areas selected for fluorescence intensity profile analyses, which are displayed in graph form. The $X$-axis shows the position along the line (pixels), and the Y-axis shows the fluorescence intensity. Bars, $6 \mu \mathrm{m}$. (C) The interaction between ALP and the EGF domain of FBLN7 was detected by far-western blotting. The EGF and CCP represent the EGF domain and CCP domain of FBLN7, respectively.

A

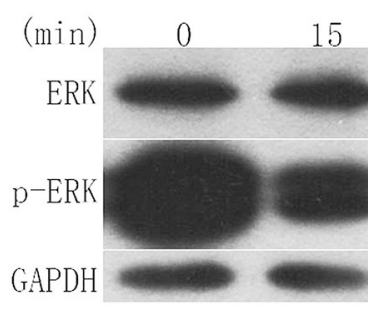

${ }^{B} \mathrm{~h}$

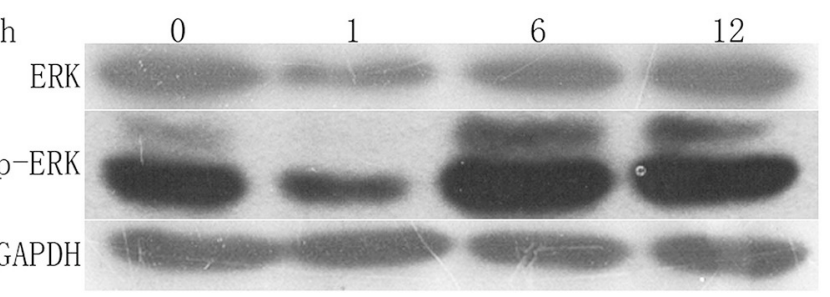

60

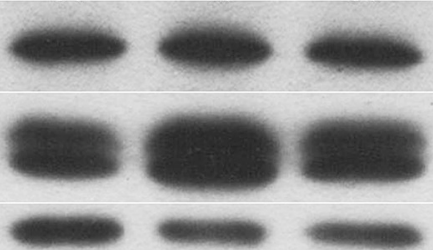

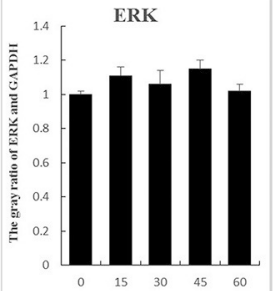
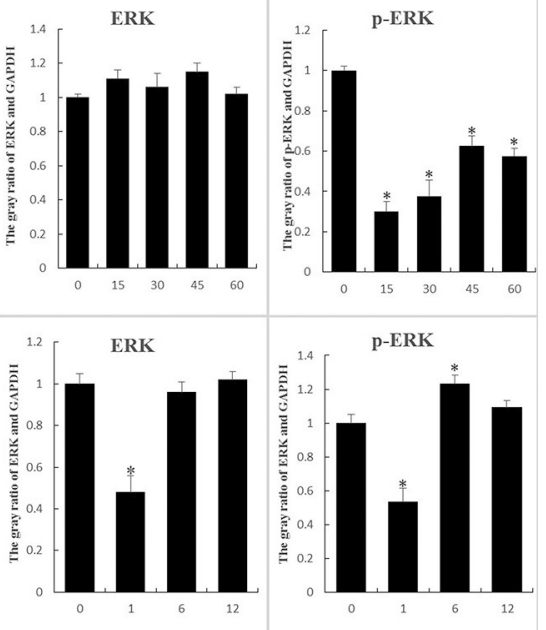

FIGURE 5 | Recombinant ALP (rALP) and S. eriocheiris stimulation of $\mathbf{3 T 6}$ cells lead to relevant protein expressions. (A) 3 T6 cells were treated with rALP $(5 \mu \mathrm{g} / \mathrm{ml})$ for 0, 15, 30, 45, and $60 \mathrm{~min}$. The protein ERK and p-ERK variation tendencies were detected by western blotting; (B) 3T6 cells were treated with S. eriocheiris for $0,1,6$, and $12 \mathrm{~h}$. The protein ERK and p-ERK variation tendencies were detected by western blotting; GAPDH served as the control. The gray value of bands were measured. Statistical significance is indicated with an asterisk $\left(^{*}\right)$.

The results showed minimal expression in the brains of unborn mice and newborn mice, while none was detected in the normal adult mouse. However, the adult mouse that was afflicted with cataract also had a small amount of expression of this protein (Figure 7A). Similar results were detected in the eye of the mouse (Figure 7B). 


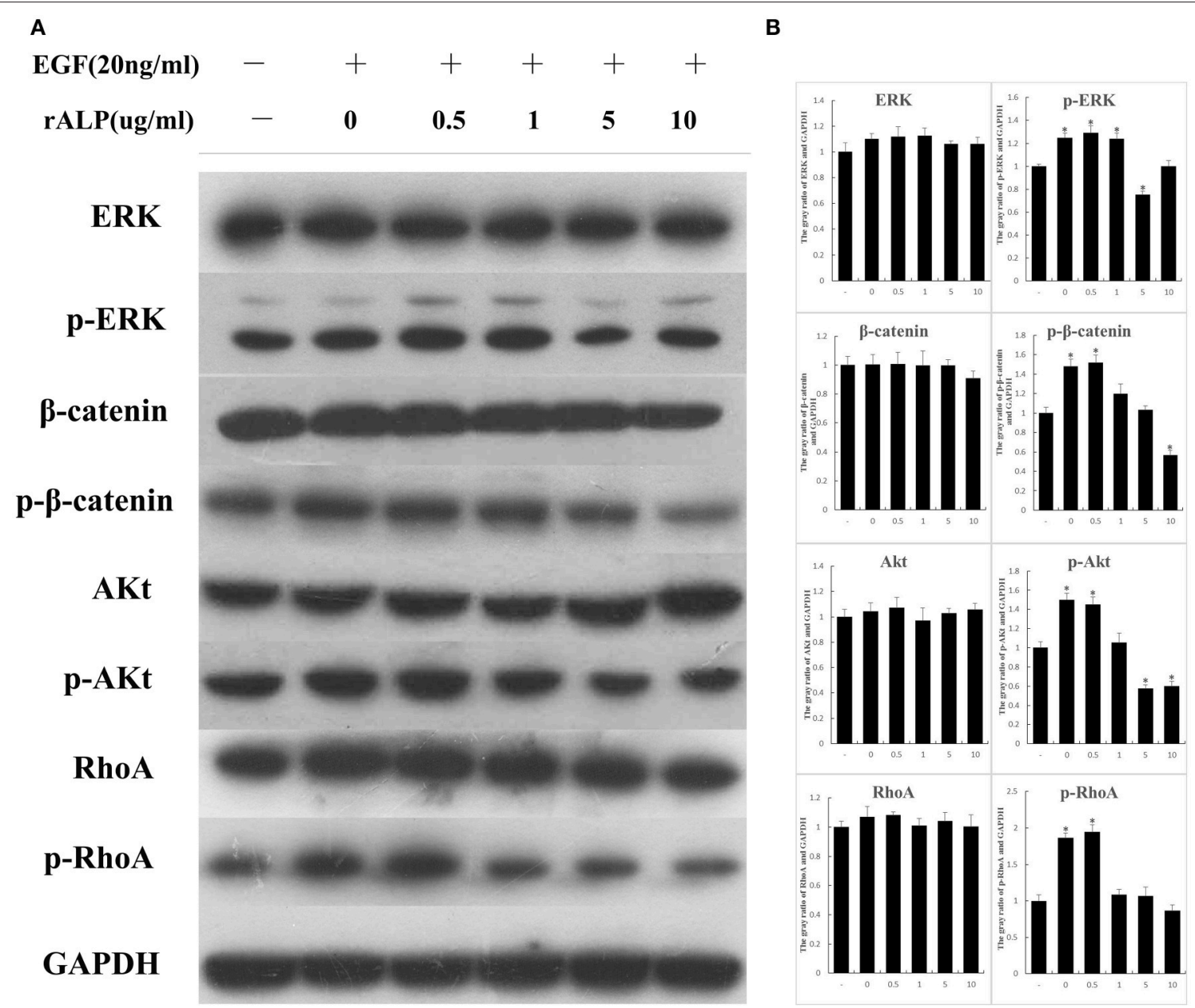

FIGURE 6 | When 3T6 cells are stimulated with EGF and treated with different concentrations of proteins, the relative protein expressions change. (A) 3 T6 cells were treated with EGF (20 ng/ml) and different concentrations of ALP protein $(0.5,1,5,10 \mu \mathrm{g} / \mathrm{ml})$ for $15 \mathrm{~min}$; untreated cells served as the control group. The protein ERK, $p$-ERK, $\beta$-Catenin, $p$ - $\beta$-Catenin, Akt, $p$-Akt, RhoA, and $p$-RhoA variation tendencies were detected by western blotting; GAPDH served as the control. (B) The gray value of bands were measured. Statistical significance is indicated with an asterisk $\left(^{*}\right)$.

\section{DISCUSSION}

S. eriocheiris was previously identified as a novel pathogen of E. sinensis and caused mass mortality in aquaculture (Wang et al., 2004b). It is interesting that besides causing infection of crustaceans among invertebrates, S. eriocheiris also infected vertebrates, e.g., newborn mice, causing cataracts as the mice grew older (Wang et al., 2003); similar to an S. mirum infection of newborn mice (Zeigel and Clark, 1974). However, S. mirum had no ability to infect crustaceans (data not yet published). Evidence of $S$. eriocheiris infections in both crustaceans and newborn mice provided an interesting proposition to experimentally examine its pathogenic mechanism.

Spiroplasma is a Mollicute species that lacks a cell wall and does not produce endotoxins and external toxins (Stülke et al., 2009), so the outer membrane proteins of Spiroplasma may play an important role involved in adhesion to and invasion of host cells. Adhesion related proteins are a group of important proteins involved in the interaction between host and pathogen. The loss of adhesion capacity by mutation results in loss of infectivity, while reversion to the cytadhering phenotype is accompanied by regaining infectivity and virulence in Mycoplasma pneumonia (Krause et al., 1982, 1983). Loss and restoration of the ability of Spiroplasma citri to adhere to a monolayer of cultured Circulifer tenellus cells is clearly associated with degradation and restoration of a specific spiroplasma membrane protein, the spiroplasma adhesin related protein (SARP1; Yu et al., 2000; Berg et al., 2001). Furthermore, the ALP of S. eriocheiris shared similarities with the adhesin-related protein SARP1 of $S$. citri (Meng et al., 2010).

In this study, we demonstrated that ALP appears to be an effector protein involved in the direct interactions with eukaryotic proteins. The immune-gold labeling and western blotting techniques both confirmed that ALP is present on the outer membrane of $S$. eriocheiris. Immunofluorescence experiments show ALP was involved in the infection of host 
A

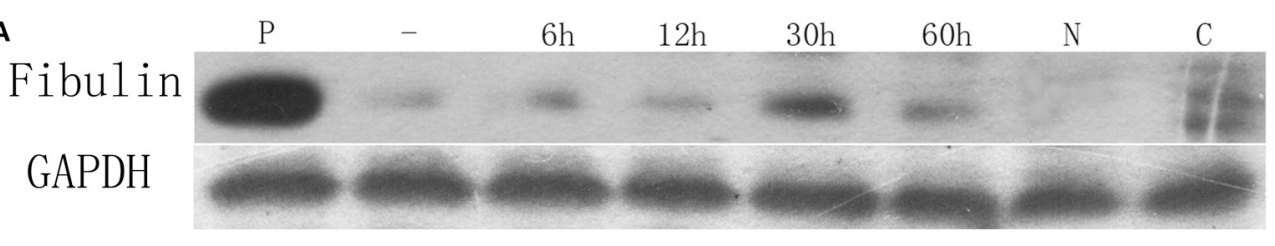

B

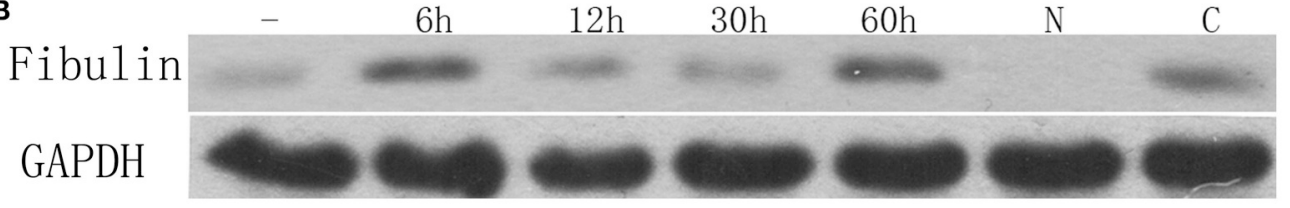

C

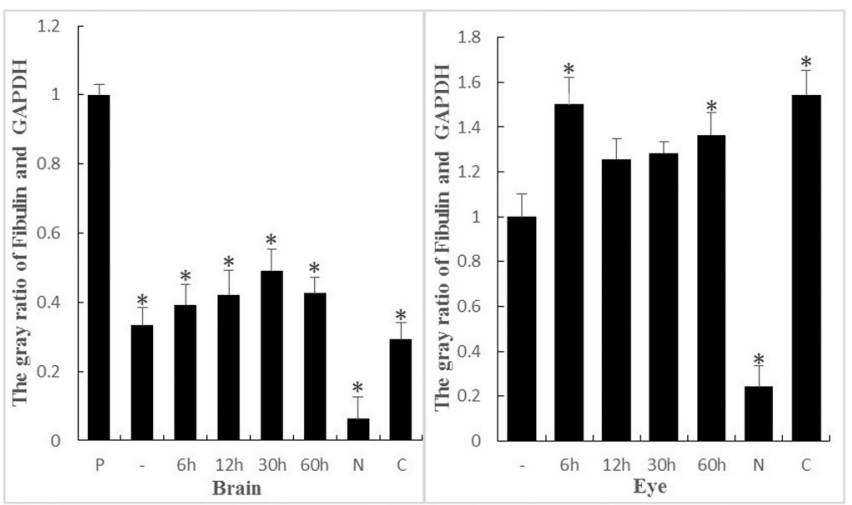

FIGURE 7 | The expression of FBLN7 during different development times of the mouse brain and eye were detected by western blotting. (A) Brain: using placenta (P) as the positive control, unborn mouse (-), mouse postnatal from 1 to $60 \mathrm{~h}$, normal adult mouse (N), and the mouse afflicted with cataracts (C); (B) Eye: unborn mouse (-), mouse postnatal from 1 to $60 \mathrm{~h}$, normal adult mouse $(\mathrm{N})$, and the mouse afflicted with cataracts (C). GAPDH served as the control, and the amount of sample used in each lane was equal. (C) The gray value of bands were measured. The Brain corresponding (A) and the Eye corresponding (B). Statistical significance is indicated with an asterisk (*).

cells by the bacterium. The ALP of S. eriocheiris was restrained when the bacteria were incubated with anti-ALP, and therefore the ability of $S$. eriocheiris to infect host cells was limited. The ALP was confirmed to be present on the outer membrane of $S$. eriocheiris and plays a crucial role in the bacterial infection of its host cells. When the ALP was restrained, it did not completely abolish S. eriocheiris infection and growth; therefore, the bacterial infection of the host may be a complex process (Figure 7C). It is necessary to find a combination of the effects of several proteins or a complex to explain the invasion of host cell types by $S$. eriocheiris.

The eukaryotic target protein of ALP was identified and confirmed by the yeast two-hybrid assay, Far-western blotting, and colocalization in HeLa cells. The EGF modules of FBLN7 were the identified interacting partners with ALP. FBLN7 has been identified as a new member of the extracellular matrix proteins, with the presence of three central tandem EGF modules and a unique Sushi domain [also known as CCP module or short consensus repeat (SCR)] at the $\mathrm{N}$ terminus (de Vega et al., 2007). The EGF-like domain is an evolutionary conserved protein domain, containing conserved carboxylate residues and structure with the epidermal growth factor (EGF). It comprises about 30-40 amino acid residues and has been found in some of animal proteins (Bork et al., 1996; Downing et al., 1996).
Most occurrences of the EGF-like domain were found in the extracellular domain of membrane-bound proteins or secreted proteins. EGF is a potent mitogenic peptide, also implicated in many non-mitogenic activities such as ion transport (Sardet et al., 1990), cellular migration (King et al., 1987), growth and development of various tissues (Carpenter and Cohen, 1997; Somboonwiwat et al., 2005), and plays a vital role in immune responses (Kansas et al., 1994; Phan et al., 2006). EGF modules are important for protein-protein interactions and bind many extracellular matrix proteins through the EGF tandem array. For instance, fibulin-1 binds to fibronectin through the EGF domain (Tran et al., 1997). At the same time, EGF-like domain also plays a key role in the process of bacterial infection of host cells. The cell wall teichoic acid (WTA) of Staphylococcus aureus, which directs interactions with the EGF-like domain of SREC-I, is a key factor that facilitates bacterial colonization in the nasal epithelial cells of humans (Baur et al., 2014). Similarly, the EGF-like domain was shown to interact with S. eriocheiris ALP in this study. It is likely that the EGF-like domain of FBLN7 binds to ALP and offer an adhesion sites for S. eriocheiris infects the host and accelerates this process. Because the Spiroplasma spp. have no cell wall, ALP may serve a role for interaction with the EGF-like domain as occurs with WTA. 
In this paper, the ability of ALP to interact with the EGFlike domain was shown. And this domain containing conserved carboxylated residues and structure with EGF, was an important stimulator of the EGFR signaling. The extracellular regulated protein (ERK) kinases signal transduction pathways in 3T6 cells were restrained when cells were treated with rALP. The ERK pathway is one of the main downstream effectors of the EGFR. It may be due to a competitive activity of ALP against EGF for the EGFR site, as the EGF has a high similarity with EGF-like domain, and then as a consequence the EGFR signaling was restrained and p-ERK was decreased. When different concentrations of rALP with EGF were used to treat the 3T6 cells, the main EGFR signaling, containing RhoA/ROCK (Rho kinase), MEK (MAPK/ERK kinase)/ERK (extracellularsignal-regulated kinase), Akt (protein kinase B), and $\beta$-catenin pathways, were decreased. Previous studies have confirmed that wild-type EGFR undergoes rapid endocytosis after binding to the plasma membrane, followed by lysosomal degradation (Shtiegman et al., 2007). The small GTPase RhoA has been identified as a negative regulator of EGFR endocytosis via its effector Rho kinase (ROCK) that regulates endophilin A1-mediated crosstalk in specific cell types. Activation of the RhoA effector ROCK phosphorylates endophilin A1 at the Thr14 amino-acid site, thus reducing the level of EGFR endocytosis (Kaneko et al., 2005). Hence, the protein competitively combines with EGF, and then the EGFR pathway is restrained upon cellular treatment with rALP; on the other hand, p-RhoA degradation results in increased EGFR internalization and therefore, the EGFR pathway is limited. When the bacteria infect the host cell, the ALP combines with EGF, thus effecting the EGFR pathway and accelerating bacterial infection of the host cell. At the same time, previous studies shown that the Akt signaling play a crucial role on the regulate of cell apoptosis. EFGR signaling play key roles in regulate cell apoptosis, cytoskeleton remodeling, cell proliferationplays and immune responses on, and so on. When S. eriocheiris infect the host cells the EGFR signaling were restrained, and the cells normal metabolism were destroyed, so the bacteria more likely to infect the cell (Riederer and Matus, 1985).

Spiroplasma mirum was confirmed to be the only species among spiroplasmas that can infect vertebrates, and it had the ability to induce cataracts in newborn suckling mice (Zeigel and Clark, 1974). Similarly, S. eriocheiris also can infect newborn mice and cause cataract, which is the second identified Spiroplasma that can infect vertebrates. Using the yeast two-hybrid assay, far-western blotting, and colocalization, we confirmed that the EGF domain of FBLN7 was the eukaryotic target protein of ALP. The prenatal, postnatal (1-60 h), and cataract mouse signals were detected at the specific band of FBLN7. There were no bands detected in any normal adult mice. These results are consistent

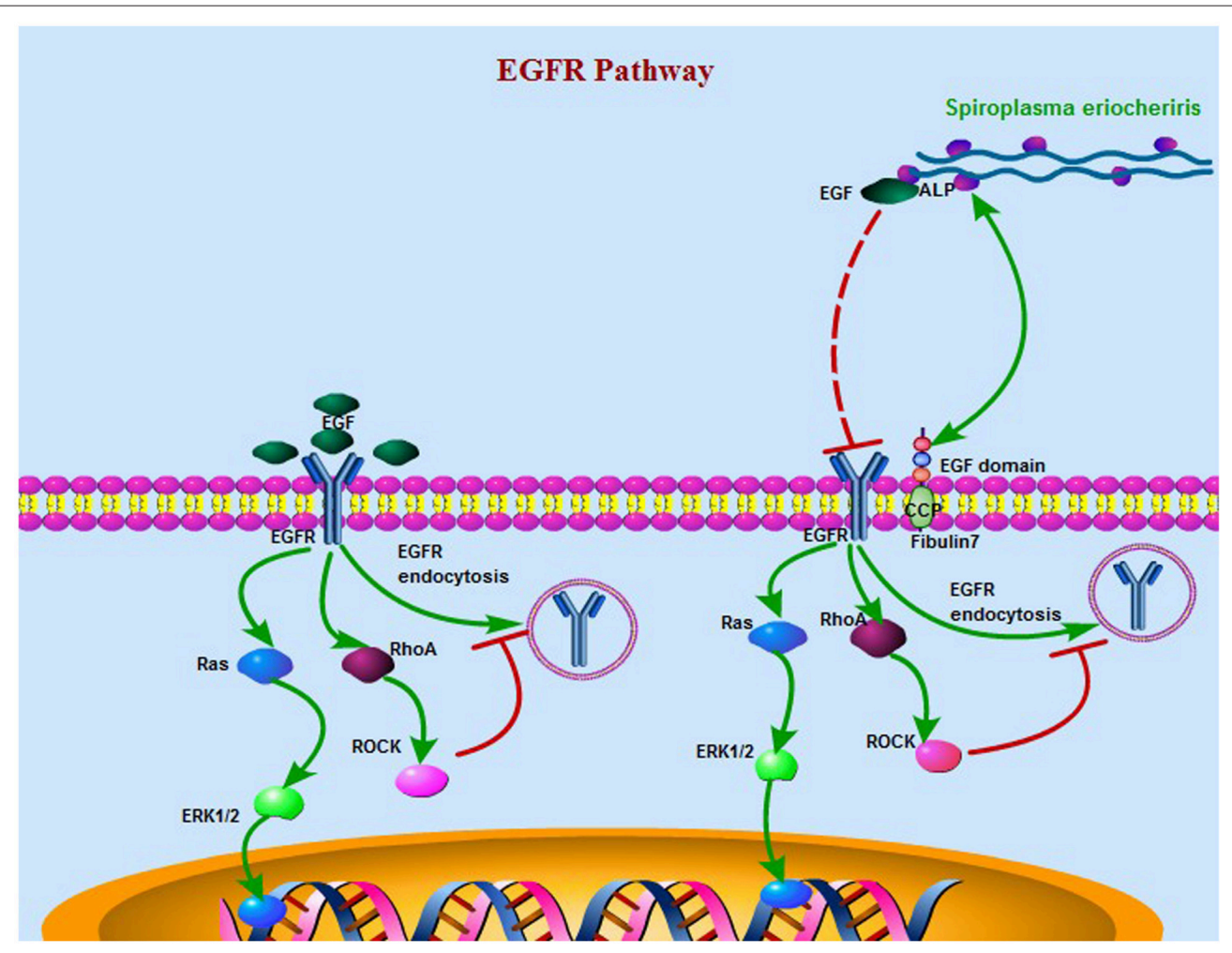

FIGURE 8 | A schematic model of the S. eriocheiris ALP interaction with the EGF domain protein to facilitate bacterial infection of the host cell when the EGFR pathway was effected by ALP. On the left is the normal EGFR pathway, and on the right is the main EGFR signaling like RhoA/ROCK (Rho kinase), MEK (MAPK/ERK kinase)/ERK (extracellularsignal-regulated kinase), etc. were decreased duo to competitive binding of ALP to EGF. The small GTPase RhoA has been identified as a negative regulator of EGFR endocytosis via its effector Rho kinase (ROCK). The fibulin7 protein duo to has servels EGF domain act as an adhesion sites of the bacteria. For abbreviations and explanations, see the text. 
with prior research showing that the expression levels of EGF appeared relatively stable during the early postnatal period and deeply dropped at postnatal 10 days (Lazar and Blum, 1992). This may be one of the reasons why newborn mice can be infected by $S$. eriocheiris, and the adult mouse is resistant to infection. There is abundant EGF in the mouse brain at an early stage after birth. Therefore, ALP promoted S. eriocheiris infection in animals by interacting with EGF. The expression levels of EGF dropped significantly several days after birth of the mice. At that point in their development, the target site of ALP was reduced. Hence, the ability of $S$. eriocheiris to infect newborn mice after several days was restricted.

In summary, this work advances our knowledge of $S$. eriocheiris pathogenesis by identifying ALP as a surface protein that is critical for infection of mammalian host cells. The EGF modules of FBLN7 were identified as the sites interacting with ALP. ALP interacts with the EGF domain protein to promote binding to and infection of the host cell. Simultaneously, the main EGFR signaling like RhoA/ROCK (Rho kinase), MEK (MAPK/ERK kinase)/ERK (extra cellular signal-regulated kinase), etc. were decreased duo to competitive binding of ALP to EGF (Figure 8). The unborn mouse, newborn mouse, and adult mouse with cataract had FBLN7. However, the normal adult mouse did not have FBLN7. Identification of S. eriocheiris effector proteins and host cell ligands such as those identified in this study will facilitate further studies to elucidate and define the molecular mechanisms involved in bacterial infections.

\section{AUTHOR CONTRIBUTIONS}

LH, QM, WW, and WG designed experiments and analyzed the data. LH, YL, QG, MN, JB, HL, and ML performed the experiments and analyzed the data. $\mathrm{LH}$ wrote the paper.

\section{REFERENCES}

Ammar, E., and Hogenhout, S. A. (2005). Use of immunofluorescence confocal laser scanning microscopy to study distribution of the bacterium corn stunt spiroplasma in vector leafhoppers (Hemiptera: Cicadellidae) and in host plants. Ann. Entomol. Soc. Am. 98, 820-826. doi: 10.1603/00138746(2005)098[0820:UOICLS]2.0.CO;2

Balish, M. F., Santurri, R. T., Ricci, A. M., Lee, K. K., and Krause, D. C. (2003). Localization of Mycoplasma pneumoniae cytadherenceassociated protein HMW2 by fusion with green fluorescent protein: implications for attachment organelle structure. Mol. Microbiol. 47, 49-60. doi: 10.1046/j.1365-2958.2003.03282.x

Baur, S., Rautenberg, M., Faulstich, M., Grau, T., Severin, Y., Unger, C., et al. (2014). A nasal epithelial receptor for Staphylococcus aureus WTA governs adhesion to epithelial cells and modulates nasal colonization. PLoS Pathog. 10:e1004089. doi: 10.1371/journal.ppat.1004089

Berg, M., Melcher, U., and Fletcher, J. (2001). Characterization of Spiroplasma citri adhesion related protein SARP1, which contains a domain of a novel family designated sarpin. Gene 275, 57-64. doi: 10.1016/S0378-1119(01)00655-2

Bi, K. R., Huang, H., Gu, W., Wang, J. H., and Wang, W. (2008). Phylogenetic analysis of Spiroplasmas from three freshwater crustaceans (Eriocheir sinensis, Procambarus clarkia and Penaeus vannamei) in China. J. Invertebr. Pathol. 99, 57-65. doi: 10.1016/j.jip.2008.06.008

Bork, P., Downing, A. K., Kieffer, B., and Campbell, I. D. (1996). Structure and distribution of modules in extracellular proteins. Q. Rev. Biophys. 29, 119-167. doi: $10.1017 /$ S0033583500005783

\section{ACKNOWLEDGMENTS}

We appreciate Professor O. Roger Anderson (Columbia University) for editing the manuscript. The current study was supported by the National Natural Science Foundation of China (NSFC Nos. 31570176; 31272686), NSFC for Talents Training in Basic Science (J1103507, J1210025), Jiangsu Agriculture Science and Technology Innovation Fund (No. CX(15)1011), Project for Aquaculture in Jiangsu Province (Grant Nos. D2015-13; Y2016-28) and the project funded by the Priority Academic Program Development of Jiangsu Higher Education Institutions (PAPD).

\section{SUPPLEMENTARY MATERIAL}

The Supplementary Material for this article can be found online at: http://journal.frontiersin.org/article/10.3389/fcimb. 2017.00013/full\#supplementary-material

Figure S1 | Spiroplasma eriocheiris has the ability to infect newborn mice and cause cataracts. The mouse on the left is a newborn pup injected with S. eriocheiris. The one on the right is a normal mouse.

Figure S2 | Coomasie stained PAGE gels used in the Western blots identified ALP localizes on the surface of S. eriocheiris. Lane M molecular-weight markers; Lane 1 membrane proteins (M), Lane 2 cytoplasmic protein (C), Lane 3 all proteins (T) of $S$. eriocheiris, respectively.

Figure S3 | Analysis of recombinant EIF and FBLN7 by SDS-PAGE. Lane 1, soluble protein of $E$. coli BL21 (DE3) with pGEX-FBLN7 after protein expression; Lane 2, insoluble protein of E. coli BL21 (DE3) insoluble protein with pGEX-FBLN7 after protein expression; Lane 3, insoluble protein of $E$. coli BL21 (DE3) insoluble protein with pGEX-EIF2 after protein expression; Lane 4, soluble protein of $E$. coli BL21 (DE3) with pGEX-EIF2 after protein expression; Lane 5, soluble protein of E. coli BL21 (DE3); Lane 6, insoluble protein of E. coli BL21 (DE3); Lane M, molecular-weight markers.

Carpenter, G., and Cohen, S. (1997). Epidermal growth factor. Annu. Rev.Biochem. 48, 193-216.

de Vega, S., Iwamoto, T., Nakamura, T., Hozumi, K., McKnight, D. A., Fisher, L. W., et al. (2007). TM14 is a new member of the fibulin family (fibulin-7) that interacts with extracellular matrix molecules and is active for cell binding. J. Biol. Chem. 282, 30878-30888. doi: 10.1074/jbc.M7058 47200

Downing, A. K., Knott, V., Werner, J. M., Cardy, C. M., Campbell, I. D., and Handford, P. A. (1996). Solution structure of a pair of calcium-binding epidermal growth factor-like domains: implications for the Marfan syndrome and other genetic disorders. Cell 85, 597-605. doi: 10.1016/S0092-8674(00)81259-3

Duncan, D. B. (1955). Multiple range and multiple F tests. Biometrics 11, 1-42.

Egan, C. A., Houston, K. M., Alcocer, M. J. C., Solovyova, A., Tate, R., Lochnit, G., et al. (2006). Lack of immunological cross-reactivity between parasite-derived and recombinant forms of ES-62, a secreted protein of Acanthocheilonema viteae. Parasitology 132, 263-274. doi: 10.1017/S00311820050 09005

Kahlon, A., Ojogun, N., Ragland, S. A., Seidman, D., Troese, M. J., Ottens, A. K., et al. (2013). Anaplasma phagocytophilum Asp14 is an invasin that interacts with mammalian host cells via its $\mathrm{C}$ terminus to facilitate infection. Infect. Immun. 81, 65-79. doi: 10.1128/IAI.00932-12

Kaneko, T., Maeda, A., Takefuji, M., Aoyama, H., Nakayama, M., Kawabata, S., et al. (2005). Rho mediates endocytosis of epidermal growth factor receptor through phosphorylation of endophilin A1 by Rho-kinase. Genes Cell 10, 973-987. doi: 10.1111/j.1365-2443.2005.00895.x 
Kansas, G. S., Saunders, K. B., Ley, K., Zakrzewicz, A., Gibson, R. M., Furie, B. C., et al. (1994). A role for the epidermal growth factor-like domain of Pselectin in ligand recognition and cell adhesion. J. Cell Biol. 124, 609-618. doi: $10.1083 /$ jcb.124.4.609

King, L. Jr., Gates, R., Nanney, L., and Stoscheck, C. (1987). Epidermal growth factor (EGF) regulates non-mitogenic functions in differentiated mammalian tissues. Process. Cutaneous Epidermal Differ. 233-252.

Kirchhoff, H., Kuwabara, T., and Barile, M. F. (1981). Pathogenicity of Spiroplasma sp. strain SMCA in Syrian hamsters: clinical, microbiological, and histological aspects. Infect. Immun. 31, 445-452.

Krause, D. C., Leith, D. K., and Baseman, J. B. (1983). Reacquisition of specific proteins confers virulence in Mycoplasma pneumoniae. Infect. Immun. 39, 830-836.

Krause, D. C., Leith, D. K., Wilson, R. M., and Baseman, J. B. (1982). Identification of Mycoplasma pneumoniae proteins associated with hemadsorption and virulence. Infect. Immun. 35, 809-817.

Lazar, L. M., and Blum, M. (1992). Regional distribution and developmental expression of epidermal growth factor and transforming growth factor-alpha mRNA in mouse brain by a quantitative nuclease protection assay. J. Neurosci. $12,1688-1697$

Liang, T. M., Li, X. L., Du, J., Yao, W., Sun, G. Y., Dong, X. H., et al. (2011). Identification and isolation of a spiroplasma pathogen from diseased freshwater prawns, Macrobrachium rosenbergii, in China: a new freshwater crustacean host. Aquaculture 318, 1-6. doi: 10.1016/j.aquaculture.2011.03.018

Lin, J., Friesen, M. T., Bocangel, P., Cheung, D., Rawszer, K., and Wigle, J. T. (2005). Characterization of Mesenchyme Homeobox 2 (MEOX2) transcription factor binding to RING finger protein 10. Mol. Cell. Biochem. 275, 75-84. doi: 10.1007/s11010-005-0823-3

Lin, T. Y., Huang, W. L., Lee, W. Y., and Luo, C. W. (2015). Identifying a neuromedin $U$ receptor 2 splice variant and determining its roles in the regulation of signaling and tumorigenesis in vitro. PLOS ONE 10:e136836. doi: 10.1371/journal.pone.0136836

Liu, L., Li, Y., Lin, J., Liang, Q., Sheng, X., Wu, J., et al. (2010). Connexin43 interacts with Caveolin-3 in the heart. Mol. Biol. Rep. 37, 1685-1691. doi: 10.1007/s11033-009-9584-5

Meng, Q. G., Li, W., Liang, T. M., Jiang, X. J., Gu, W., and Wang, W. (2010). Identification of adhesin-like protein ALP41 from Spiroplasma eriocheiris and induction immune response of Eriocheir sinensis. Fish Shellfish Immunol. 29, 587-593. doi: 10.1016/j.fsi.2010.06.005

Moulder, R. W., French, F. E., and Chang, C. J. (2002). Simplified media for spiroplasmas associated with tabanid flies. Can. J. Microbiol. 48, 1-6. doi: 10.1139/w01-128

Ojogun, N., Kahlon, A., Ragland, S. A., Troese, M. J., Mastronunzio, J. E., Walker, N. J., et al. (2012). Anaplasma phagocytophilum outer membrane protein A interacts with sialylated glycoproteins to promote infection of mammalian host cells. Infect. Immun. 80, 3748-3760. doi: 10.1128/IAI.00654-12

Phan, U. T., Waldron, T. T., and Springer, T. A. (2006). Remodeling of the lectin-EGF-like domain interface in P- and L-selectin increases adhesiveness and shear resistance under hydrodynamic force. Nat. Immunol. 7, 883-889. doi: $10.1038 /$ ni1366

Regassa, L. B., and Gasparich, G. E. (2006). Spiroplasmas: evolutionary relationships and biodiversity. Front. Biosci. 11, 2983-3002. doi: 10.2741/2027

Riederer, B., and Matus, A. (1985). Differential expression of distinct microtubuleassociated proteins during brain development. Proc. Natl. Acad. Sci. U.S.A. 82, 6006-6009. doi: 10.1073/pnas.82.17.6006

Rottem, S. (2002). Interaction of mycoplasmas with host cells. Physiol. Rev. 83, 417-432. doi: 10.1152/physrev.00030.2002

Salman, M., and Rottem, S. (1995). The cell membrane of Mycoplasma penetrans: lipid composition and phospholipase A1 activity. Biochim. Biophys. Acta 1235, 369-377. doi: 10.1016/0005-2736(95)80026-C

Sardet, C., Counillon, L., Franchi, A., and Pouyssegur, J. (1990). Growth factors induce phosphorylation of the $\mathrm{Na}^{+} / \mathrm{H}^{+}$antiporter, glycoprotein of $110 \mathrm{kD}$. Science 247, 723-726. doi: 10.1126/science.2154036

Shtiegman, K., Kochupurakkal, B. S., Zwang, Y., Pines, G., Starr, A., Vexler, A., et al. (2007). Defective ubiquitinylation of EGFR mutants of lung cancer confers prolonged signaling. Oncogene 26, 6968-6978. doi: 10.1038/sj.onc. 1210503
Somboonwiwat, K., Marcos, M., Tassanakajon, A., Klinbunga, S., Aumelas, A., Romestand, B., et al. (2005). Recombinant expression and antimicrobial activity of anti-lipopolysaccharide factor (ALF) from the black tiger shrimp Penaeus monodon. Dev. Comp. Immunol. 29, 841-851. doi: 10.1016/j.dci.2005.02.004

Stülke, J., Eilers, H., Schmidl, S. R. (2009). “Mycoplasma and spiroplasma," in Encyclopedia of Microbiology, ed M. Schaechter (Oxford: Academic Press), 208-219.

Suzuki, S., Oshima, K., Kakizawa, S., Arashida, R., Jung, H. Y., Yamaji, Y., et al. (2006). Interaction between the membrane protein of a pathogen and insect microfilament complex determines insectvector specificity. Proc. Natl. Acad. Sci. U.S.A. 103, 4252-4257. doi: 10.1073/pnas.0508668103

Tran, H., VanDusen, W. J., and Argraves, W. S. (1997). The self-association and fibronectin-binding sites of fibulin-1 map to calcium-binding epidermal growth factor-like domains. J. Biol. Chem. 272, 22600-22606. doi: $10.1074 /$ jbc.272.36.22600

Tseng, Y. T., Wang, S. M., Huang, K. J., Lee, A. I., Chiang, C. C., and Wang, C. T. (2010). Self-assembly of severe acute respiratory syndrome coronavirus membrane protein. J. Biol. Chem. 285, 12862-12872. doi: 10.1074/jbc.M109.030270

Tully, J. G., Whitcomb, R. F., and Bové, J. M. (1982). Spiroplasma mirum, a new species from the rabbit tick (Haemaphysalis leporispalustris). Int. J. Syst. Bacteriol. 32, 92-100. doi: 10.1099/00207713-32-1-92

Wang, W., Chen, J., Du, K., and Xu, Z. (2004a). Morphology of spiroplasmas in the Chinese mitten crab Eriocheir sinensis associated with tremor disease. Res. Microbiol. 155, 630-635. doi: 10.1016/j.resmic.2004.04.010

Wang, W., Gu, W., Gasparich, G. E., Bi, K. R., Ou, J. T., Meng, Q. G., et al. (2011). Spiroplasma eriocheiris sp. nov., associated with mortality in the Chinese mitten crab, Eriocheir sinensis. Int. J. Syst. Evol. Microbiol. 61, 703-708. doi: 10.1099/ijs.0.020529-0

Wang, W., Rong, L. W., Gu, W., Du, K. H., and Chen, J. X. (2003). Study on experimental infections of Spiroplasma from the Chinese mitten crab in crayfish, mice and embryonated chickens. Res. Microbiol. 154, 677-680. doi: 10.1016/j.resmic.2003.08.004

Wang, W., Wen, B., Gasparich, G. E., Zhu, N., Rong, L., Chen, J., et al. (2004b). A spiroplasma associated with tremor disease in the Chinese mitten crab (Eriocheir sinensis). Microbiology 150, 3035-3040. doi: 10.1099/mic.0.26664-0

Wayadande, A. C., and Fletcher, J. (1998). Development and use of an established cell line of the leafhopper Circulifer tenellus to characterize Spiroplasma citri-vector interactions. J. Invertebr. Pathol. 72, 126-131. doi: 10.1006/jipa.1998.4753

Xiu, Y. J., Wu, T., Meng, X. H., Meng, Q. G., and Wang, W. (2015). Identification and isolation of a spiroplasma pathogen from diseased oriental river prawn, Macrobrachium nipponense, in China: a new freshwater crustacean host. Aquaculture 437, 270-274. doi: 10.1016/j.aquaculture.2014.12.010

Yu, J., Wayadande, A. C., and Fletcher, J. (2000). Spiroplasma citri surface protein P89 implicated in adhesion to cells of the vector Circulifer tenellus. Phytopathology 90, 716-722. doi: 10.1094/PHYTO.2000.90.7.716

Zeigel, R. F., and Clark, H. F. (1974). Electron microscopy of the suckling mouse cataract agent: a noncultivable animal pathogen possibly related to mycoplasma. Infect. Immun. 9, 430-443.

Conflict of Interest Statement: The authors declare that the research was conducted in the absence of any commercial or financial relationships that could be construed as a potential conflict of interest.

The reviewer PT and handling Editor declared their shared affiliation and the handling Editor states that the process nevertheless met the standards of a fair and objective review

Copyright (c) $2017 \mathrm{Hou}$, Liu, Gao, Xu, Ning, Bi, Liu, Liu, Gu, Wang and Meng. This is an open-access article distributed under the terms of the Creative Commons Attribution License (CC BY). The use, distribution or reproduction in other forums is permitted, provided the original author(s) or licensor are credited and that the original publication in this journal is cited, in accordance with accepted academic practice. No use, distribution or reproduction is permitted which does not comply with these terms. 